\title{
Remarks documented on medico- legal examination forms on sexual abuse cases; are they properly comprehended by the police?
}

\author{
Kitulwatte IDG ${ }^{1}$, Rajapaksha WRAS ${ }^{1}$, Edirisinghe $P A S^{1}$, Perera WNS ${ }^{1}$, Wijerathna NASP ${ }^{1}$, \\ Sihanada $A A S^{1}$, Bulathsinhala $B A A R^{1}$, Gunathilake $R^{1}$ \\ Department of Forensic Medicine, Faculty of Medicine, Ragama
}

*Corresponding author: Tel: 0094-71-961237. E-mail address: indiradgk@yahoo.com

MLJSL. Vol 1. No 2. Aug. pp 23 - 27

\begin{abstract}
Introduction : Expert medical evidence is widely used in sexual abuse cases, but its contribution to the progress of legal cases is unclear. Poor understanding of the remarks given by the medical officers in a Medico Legal Examination Form (MLEF) in alleged sexual abuse cases by the police officers may affect effective administration of justice.

Objective: This study is mainly aimed at assessing the degree of understanding by the police officers' when reading three commonly expressed medico-legal remarks in cases of alleged sexual abuse. Secondly, to identify the areas of poor understanding, for which interventions need to be carried out.

Study Design: Cross sectional descriptive study was conducted among 64 police officers, in the rank of police constables and sergeants from western province, who are attending to routine work of a police station (criminal investigations, children and women's desk and traffic unit). Data collection was done by self administered questionnaire after a briefing regarding the study and instructions on how to fill the questionnaire.

Results: $72 \%$ of the officers believed that they understood the statements written on MedicoLegal Examination Form (MLEF) when it is in native language while only $32 \%$ believed so for statements in English. However the analysis of the correct responses revealed that only $28.9 \%$ of officers understood the exact meaning in native language while it was $10.4 \%$ for English. The understanding about the statement on absence of medical evidence to confirm or exclude the allegation when given in Sinhala was $26.6 \%$ while it was $10.9 \%$ in English. The statement on evidence of vaginal penetration has been correctly understood by $20.3 \%$ in Sinhala while it is $7.8 \%$ in English.

Conclusion: Statements made in native language are approximately three times better understood than the ones made in English. However, overall understanding of the remarks made by doctors was very poor. It is high time we take necessary actions to intervene if our goal is effective administration of justice.
\end{abstract}

Key words: Remarks, Medico Legal Examination Form, sexual abuse, police, understanding 


\section{Introduction}

Sexual abuse is a significant public health problem across the world. In 2008 the United Nations Security Council adopted a resolution which declared rape to be a threat to global security [1]. The act of reporting a case of sexual abuse and the subsequent legal process is complicated. There are many stages involved in this action and the victims may drop out at any one of these stages. A successful trial procedure cannot be carried out on the victim's statement alone. Corroboration with other evidence is essential to lead a strong trial. Expert medical evidence is widely used in sexual abuse cases; but whether such evidence is properly utilized by the concerned parties for the progress of legal cases is unclear [2]. Close coordination and cooperation between police authorities and the clinicians is desired in respect of medico-legal cases. At the completion of examination of an alleged victim/assailant of sexual assault, it is the duty of the forensic medical specialist or the medical officer performing medico -legal duties to convey a summary of the examination findings to the police. In Sri Lanka this is done by doctors recording the findings in the police copy of the Medico Legal Examination Form (MLEF). Information given as such includes, presence or absence and type of injury, type of force necessary to inflict such injuries, category of hurt, presence or absence of consumption of liquor, presence or absence of sexually transmitted disease and presence or absence of evidence of sexual activity. Police on receiving such information decide on the indictment of the case. Thus, it is extremely important to convey the correct information to the police. However, since there is no special cell to mark about evidence of sexual activity in the existing Sri Lankan MLEF, doctors often write an explanatory remark to help the police to understand the outcome of the examination. This is written in either the native language or English. Poor understanding of the medical officer's remarks in the MLEF by the police affects effective administration of justice and will lead to inadequate utilization of medical findings

\section{Objective:}

Our first objective was to provide an over view of the understanding of the police officers on three commonly used expert medico-legal opinions expressed by a medical officer in a MLEF in cases of alleged sexual abuse. Second objective was to assess the areas of poor understanding, for which interventions can be made.

\section{Study Design:}

Cross sectional descriptive study was conducted among 64 police officers who were actively involved in routine work of police station i.e criminal investigations, children and women's desks, and traffic units. The officers were mainly of the ranks of constables and sergeants from two police stations in the Western Province. The pretested self administered questionnaire was distributed to police officers after a briefing regarding the study and instructions on how to fill the questionnaire. Informed consent was obtained from the individuals participating in the study and the officer in charge of the police station. 3 commonly 
expressed remarks by the medical officers were selected for the study area. They are;

1. There is no medical evidence of penetrative sexual intercourse. However the allegation of intracrural intercourse cannot be excluded or confirmed

2. There is medical evidence of vaginal penetration

3. There is a hymenal laceration

The remarks were given in both English and Sinhala and the questions were asked in Sinhala. The questionnaire was designed according to the standard procedures in setting multiple choice answers to reduce interpreter bias.

\section{Results:}

The overall belief of the officers with regards their understanding about the remarks, calculated by considering the mean for 3 special remarks was $72 \%$ in native language while it was $32 \%$ in English. There was a significant difference ( $p$ value 0.000 ) between the 2 languages. However when we considered the overall mean percentage for correct responses, only $28 \%$ of the officers had a clear understanding of the remarks when given in Sinhala while it was $10.4 \%$ for English. P value between the two groups, Sinhala and English was 0.001.

Out of 64 police officers 40 officers $(63 \%)$ believed that they had understood the remarks expressed by the doctors regarding intracrural intercourse when it was written in native language while it was only 18 officers (28\%) when given in English. The correct response on this remark was marked by 17 officers $(27 \%)$ when given in Sinhala, while only 7 officers $(11 \%)$ in English. P value between the two groups was 0.026 showing significance.
The statement on medical evidence of vaginal penetration was believed to be understood by 44 out of 64 officers (69\%) when given in native language while it was only 22 officers (34\%) when given in English. It was observed that 13 out of 64 officers (20\%) had marked the correct response on this question when given in Sinhala while it was only 5 out of 64 (8\%) in English. P value between the two groups was 0.047 still showing a significant difference between the two groups.

54 officers out of 64 (84\%) believed that they have a correct understanding about the statement on presence of hymenal laceration when stated in native language while it was 21 (33\%) in English. The correct response was selected by 24 out of 64 officers (37.5\%) in Sinhala while it was only $8(12.5 \%)$ when stated in English. P value was 0.001 .

\section{Discussion}

The initial step in the indictment in a case of alleged sexual abuse takes place at the police station once the medico legal examination of the parties is complete. Medical examination plays an important role in proving or disproving the allegations in cases of sexual abuse. [3] Mere presence of symptoms cannot prove that sexual abuse has occurred since the alleged symptoms in these cases can have several possible explanations. Therefore it is extremely important to do a proper medical examination to scientifically clarify how the symptom varies with situations. Still at the end of the medical examination offering a definite opinion on the allegation is difficult in a considerable number of cases. Therefore the medical expert needs to elaborate his opinion with an explanatory 
remark. The opinion stated in these remarks should be correctly understood by the police for them to take further actions. Dropout rate prior to involvement of the Judiciary in alleged sexual abuse cases are high.[4] Inappropriate or inadequate understanding of the medical remarks may have a clear impact on this.

The study revealed that the overall belief of the police officers about their understanding of the three specific medico -legal remarks mentioned above is satisfactory $(72 \%)$ in native language while it is very poor (32\%) in English. This can be expected in a country where there is a poor literacy rate in English even among teachers. [5] However, though the officers felt comfortable with the statements made in native language their overall correct understanding of the statements was very poor in both languages though there was a significant difference between the two languages regardingcorrect understanding (28\% in Sinhala and $10 \%$ for English). This needs to be addressed widely, in order to ensure effective administration of justice.

Remarks on intracrural intercourse were correctly understood by $27 \%$ when given in Sinhala while it was only $11 \%$ when given in English. Positive medical findings are only present in a minority of cases in intracrural intercourse. [6] Therefore a conclusive opinion cannot be given using the medical examination findings alone. Incorrect understanding of the remarks on this can lead to adverse social and legal consequences for the victim, the family and the alleged offender. Though there is a significant difference in understanding of the remarks in the two languages, only approximately one fourth got it correct even in their native language.
Evidence of vaginal penetration is an important remark in a case of alleged sexual abuse. The forensic examiner may come to such a conclusion based on the findings in the genitalia as well as from results of investigations. Poor understanding (20\%) of such straightforward remarks by the police officers even when it was given in native language indicates the seriousness of the problem. There is an existing poor agreement between the medical experts specially forensic and non forensic doctors regarding the interpretation on hymenal lacerations due to normal anatomical variations. [7] However, once a forensic examiner has arrived at a conclusion it should be clearly intimated to the police for further actions. Here again the study group showed a very poor response, $37.5 \%$ in Sinhala and $12.5 \%$ in English.

Deficiencies regarding the knowledge on child abuse investigations have been observed previously in Sri Lanka in a study conducted in the Central Province [8]. The poor understanding of the medico-legal remarks given by experts in the present study confirms that deficiency is more serious and appropriate interventions should commence as a matter of priority.

\section{Limitations of the study}

The study population included the police officers involved in the routine duties of a police station and we did not compare the knowledge among various groups of police officers such as women's desk Vs others since officers are transferred regularly from one section to another without obtaining any special training. Thus, it is believed that an ordinary policeman should have a general idea about all criminal aspects. Furthermore, the study was not specifically 
aimed at the higher officials who are involved in decision making. Thus, although at a glance the findings seems to be very bleak one may argue that the knowledge of a police officer who is involved in routine duty of the station does not need to have an understanding of the remarks because the cases are supervised by the officer in charge of the station. Therefore, further studies are needed involving police officers who are responsible in the decision making process in alleged sexual assault cases.

\section{Conclusions and recommendations}

The study revealed that there are serious and substantial amount of errors in understanding the three remarks that were tested in this study. As a result the investigations of cases of sexual abuse are evidently not in accordance with the requirements of the country. The overall perception by the police officers of the medico-legal remarks made by the medical officers in cases of sexual abuse is very poor. Approximately one third to quarter of the officers had a clear understanding of the message even when it was given in native language. There is a significant difference in the understanding of the remarks when made in native language compared to the ones made in English.

The findings also highlight the need of good inter disciplinary communication between the police and the medical officers in assisting in the administration of justice to both victims and the alleged perpetrators of sexual abuse. Therefore, our recommendation is to instruct the medical officers involved in forensic medical examination of cases of sexual abuse to make their remarks in the native language and to give further verbal explanations with regards to theses remarks when necessary. We also suggest that modifications to the existing medico -legal examination form need to be done to include specific remarks on cases of sexual abuse in all three languages. Police officers involved in the investigation of cases of sexual abuse need to be trained regarding the interpretation of opinions expressed by medical experts in the remarks column of MLEF to assist in the proper investigation into these cases. We also propose development of training modules for police officers to be conducted at the provincial level by specialists in Forensic Medicine in that area.

\section{References}

1. Mahima Achuthan and Renee Black, United Nations Security Council Resolution 1820, A Preliminary Assessment of the Challenges and Opportunities,1820 Strategy Session, International Women's Tribune Centre, New York, September 2009

2. Du Mont J, White D (2007) The uses and impacts of medico-legal evidence in sexual assault cases: a global review. Geneva: World Health Organisation

3. Carol P. Herbert, Expert medical assessment in determining probability of alleged child sexual abuse, Child Abuse \& Neglect, Volume 11, Issue 2, 1987, Pages 213-221

4. high worldwide. [Bo Edvardsson, Errors in investigations of disputable cases of child sexual abuse, 11th European Conference on Psychology and Law, Lisbon, Portugal, June 5-8, 2001

5. Gayan Ratnayake, United Nations Educational, Scientific and Cultural Organization (UNESCO) Bangkok's ICT in Education News, January 112007 
6. W. D. S. McLay, Clinical Forensic Medicine, $2^{\text {nd }}$ edition, Cambridge University Press, 1996.

7. Kathi L. Makoroff, Jamie L. Brauley, Ann M. Brandner, Patricia A. Myers, Robert A. Shapiro, Genital examinations for alleged sexual abuse of prepubertal girls: findings by pediatric emergency medicine physicians compared with child abuse trained physicians, Child Abuse \& Neglect 26 (2002) 1235-1242

8. Vadysinghe AN, Ranmohottige USN, Weerakkody IR, Aluthgedara R. Is knowledge on " Medico-legal aspect of child abuse" adequate among police officers who are more than 10 years in police service in central province. Proceeding of Annual Scientific Sessions 2010, Medico-Legal Society, Sri Lanka

\section{Contribution of authors}

Design to the study - IDGK, PASE, WRASR, WNSP, NASPW, AASS, BAARB, and RG

Supervision to the study- IDGK

Analysis of the data- IDGK, AASS, BAARB Interpretation of the results- IDGK, PASE

Writing the manuscript -IDGK

Revising the manuscript-IDGK, PASE 